\title{
Moral Distress and Its Associated Factors Among Nurses in Northwest Amhara Regional State Referral Hospitals, Northwest Ethiopia
}

This article was published in the following Dove Press journal: Psychology Research and Behavior Management

\author{
Alemshet Yirga Berhie' \\ Zewdu Baye Tezera ${ }^{2}$ \\ Abere Woretaw Azagew (iD) ${ }^{3}$ \\ 'Department of Surgical Nursing, School \\ of Nursing, College of Medicine and \\ Health Sciences, University of Gondar, \\ Gondar, Ethiopia; ${ }^{2}$ Department of \\ Comprehensive Nursing, School of \\ Nursing, College of Medicine and Health \\ Sciences, University of Gondar, Gondar, \\ Ethiopia; ${ }^{3}$ Department of Medical \\ Nursing, School of Nursing, College of \\ Medicine and Health Sciences, University \\ of Gondar, Gondar, Ethiopia
}

Correspondence: Abere Woretaw Azagew

Tel +251918198921

Email wabere@ymail.com
Background: Moral distress is the cognitive-emotional dissonance that arises when one feels compelled to act against one's moral requirements. The study aimed to assess the proportion of moral distress and associated factors among nurses working in Northwest Amhara Regional State referral hospitals in 2018.

Methods: A cross-sectional study was conducted among nurses working at Northwest Amhara regional state referral hospitals from April 1-30/2018. A total of 423 study participants were enrolled in the study. A systematic random sampling technique was used to select the study participants. A pretested self-administered structured questionnaire was used to collect data. Moral Distress Scale-Revised (MDS-R) was used to assess the proportion of moral distress. Epi info version 7 for data entry and SPSS version 22 for data analysis were used. A binary logistic model was computed. Variables having p-value $<0.5$ with $95 \% \mathrm{CI}$ were used to declare the presence of significant associations.

Results: A total of 423 study participants were enrolled in the study with a response rate of $97.4 \%$. The mean (SD) age of the respondents was $30.62 \pm 5.7$ years. The majority of nurses $350(85 \%)$ were degree and above holders in nursing. The proportion of moral distress among nurses was found to be $83.7 \%$. Work experience 11-20 years [adjusted odds ratio $(\mathrm{AOR})=2,95 \% \mathrm{CI}: 1.01,3.34]$, perceived poor team communication $[\mathrm{AOR}=4.5,95 \%$ CI: $1.78,11.62]$, perceived powerlessness in decision making [AOR=3.3, 95\% CI: 1.38 , 7.87], inadequate staffing [AOR $=2.96,95 \% \mathrm{CI}: 1.26,6.97]$, and inappropriate provision of care $[\mathrm{AOR}=4.12,95 \% \mathrm{CI}: 1.55,10.9]$ were significantly associated with moral distress.

Conclusion: Nurses frequently experienced moral distress in clinical settings. Perceived poor communication, perceived powerlessness in decision making, inadequate staffing, and inappropriate provision care were the factors associated with moral distress.

Keywords: moral distress, nurse, prevalence, proportion

\section{Background}

According to Andrew Jameton in 1994, Moral distress(MD) occurs "when one knows the ethically correct action to take but feels powerless to take that action". 1,2 It is the negative feelings that arise when one knows the right course of action to take but is not able to act on it due to constraints or restrictions of workplace environment, time, and authority. ${ }^{3,4} \mathrm{MD}$ is the experience of frustration and failure arising from an individual's struggle to fulfill their moral obligations to patients, families, and the public. ${ }^{5}$ It is the cognitive-emotional dissonance that arises when one feels compelled to act against one's moral requirements. Moral distress is 
common in clinical practice because caring for the patient is a natural moral activity. ${ }^{6}$ Clinical care involves the interfacing of multiple moral actors. ${ }^{6,7} \mathrm{MD}$ is not isolated to one geographical location. ${ }^{8}$ In the United States, one in three nurses experiences moral distress. ${ }^{9}$ The source of moral distress may vary but it is associated with in disagreement in the patient care plan, not involved in decision making, restraint of healthcare resources, inadequate staffing, a continuation of futile patient care, poor communication and restricting patient's autonomy. ${ }^{4}$ Moral distress has a deleterious effect on patients, nurses, and organizations which results in decreased job satisfaction, increased turnover, withdrawal from a job, and developing physical and psychological symptoms. ${ }^{10}$ Moral distress hurts nursing practice and the patient treatment outcome as well as their performance and wellbeing that can influence the quality, quantity, and cost of nursing care. ${ }^{11}$ Moral distress affects nurses' personality as well as their ability to work and continue working on the same unit. ${ }^{12}$ Moral distress is facing the nursing profession because nurses are involved in all areas of healthcare. ${ }^{13}$ Therefore, nurses can lose their capacity to care, fail to provide good care, devoid of patient contact, become emotionally aloof, deny their emotional pain, and become cynical and sarcastic. ${ }^{11}$ Moral distress varies from individual to individual. When nurses cannot do what they think is right, they experience moral distress. ${ }^{14}$ As a result, this study tries to investigate the proportion of moral distress among nurses in Northwest Amhara regional state referral hospitals.

\section{Methods}

\section{Study Design and Setting}

A cross-sectional study was conducted from April 1-30/2018. The study was conducted among nurses working in Northwest Amhara Regional State Referral Hospitals. Currently, there are three referral hospitals found in Amhara Regional State namely; Gondar University Referral Hospital (GURH), Felege Hiwot Referral Hospital (FHRH), and Debre Markos Referral Hospital (DMRH). Around 1155 nurses were working in these hospitals of those 598 nurses who were found in GURH, 327 nurses in FHRH, and 230 nurses in DMRH.

\section{Source and Study Population}

All nurses working in Northwest Amhara Regional State Referral hospitals were considered as the source population, whereas nurses working in the selected referral hospitals during the data collection period taken as the study population.

\section{Sample Size and Sampling Procedure}

The sample size was determined using the single population proportion formula through the Epi Info Stat Calc program with the assumption of; 95\% level of confidence, $5 \%$ margin of error, and 50\% of the proportion of MD. With this assumption, the estimated sample size was 384 . Taking a $10 \%$ non-response rate, the final sample size was 423. The study participants were taking from each referral hospital with proportional allocation. The sampling frame was taken from each hospital matron office and the sampling unit was estimated. Then using a systematic random sampling method each study participant was selected in every person pattern (Figure 1).

\section{Data Collection Tools and Procedures}

Data collection was performed using a structured questionnaire consisting of two parts. The first part focused on sociodemographic characteristics and the second part is on moral distress measurement. Corley's Moral Distress Scale (MDS) revised by Harmic (MDS-R) was used to measure the presence as well as the frequency of moral distress. The MDS-R consists of 21 items that describe morally distressing situations. Responses are given on a 5 point Likert scale ranging from 0 (never), 1(rarely), 2 (sometimes), 3 (often), and 4 (always/very frequently). For each item, a composite score is computed by multiplying the frequency and intensity

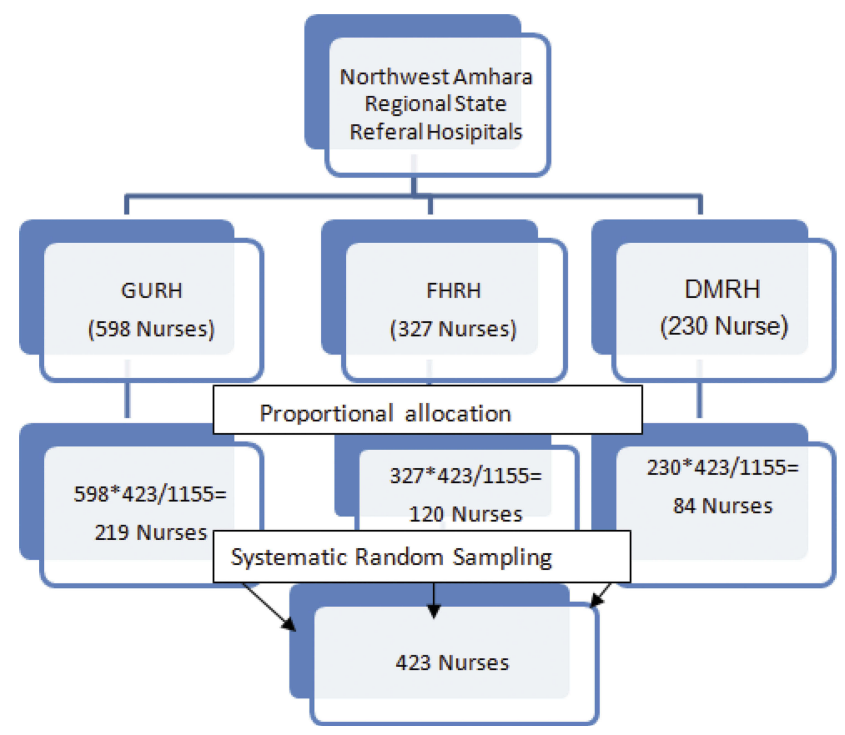

Figure I A flow chart shows the proportion of Nurses taking from Northwest Amhara Regional State Referral Hospital, 2018. 
scores. The total MDS-R score is obtained by summing up frequency multiplying by intensity scores and the result ranged between $0-16$, and the total range is from 0 to 336 . The Cronbach $\alpha$ or reliability test of the tool was $0.89 .{ }^{15}$ Taking the summed responses those nurses who gave a response of rarely, sometimes, often, and always considered as having moral distress whereas study participants who gave never response considered as having no moral distress. Three-degree holder midwife nurses and three health officer supervisors have participated in the data collection process.

\section{Data Processing and Analysis}

The data were checked, coded, and entered into the Epi Info version seven, and exported to SPSS version twenty for analysis. Descriptive statistics such as means, frequencies, and percentages were used. Tables and bar graphs were used to display the findings. The binary logistic regression model was used to identify factors associated with moral distress. All variables whose $p$-value $\leq 0.2$ in the bivariable logistic regression analysis were taken into multivariable logistic regression analysis. For the bivariable logistic regression; Crude Odds Ratio (COR) with 95\% CI, and for the multivariable logistic regression; an AOR with $95 \% \mathrm{CI}$ was calculated. The variables having p-value $<0.05$ in the multivariate logistic regression model were considered as statistically significant and independently associated with moral distress. The backward stepwise logistic regression analysis method was used. Hosmer's and Lemeshow goodness of fit test was done.

\section{Results}

\section{Socio-Demographic Characteristics of the Respondents}

A total of 423 participants were enrolled in the study with a response rate of $412(97.4 \%)$. The above half (55\%) of the participants were female. The mean (SD) age of the respondents was $30.62 \pm 5.7$ years. Nearly half $(51.7 \%)$ were married, the majority (90\%) were Orthodox Christian, and (88.1\%) were Amhara by ethnicity. The majority of nurses $350(85 \%)$ were degree and above holders in nursing. One hundred ninety-five (47.1\%) were junior nurses. The mean (SD) work experience was $6.9 \pm 5$ years, and 237 (57.5\%) nurses were worked in the day/night shift schedule. Their mean (SD) salary was $176.37 \pm 2.3$ USD per month (Table 1 ).

\section{The Proportion of Moral Distress}

The overall proportion of nurses who reported moral distress was found to be 345 [83.7\% (95\% CI: 79.6, 87.4\%)]. The
Table I Frequency Distribution of Socio-Demographic Characteristics of Nurses in Northwest Amhara Regional State Referral Hospitals, Northwest, Ethiopia, $2018(n=412)$

\begin{tabular}{|c|c|c|c|}
\hline Variables & Categories & Frequency (n) & Percent (\%) \\
\hline \multirow[t]{2}{*}{ Sex } & Female & 227 & 55.1 \\
\hline & Male & 185 & 44.9 \\
\hline \multirow[t]{4}{*}{ Age (years) } & $<30$ & 265 & 64.3 \\
\hline & $30-34$ & 55 & 13.3 \\
\hline & $35-39$ & 53 & 12.9 \\
\hline & $>39$ & 39 & 9.5 \\
\hline \multirow[t]{2}{*}{ Marital status } & Married & 213 & 51.7 \\
\hline & Unmarried & 199 & 48.3 \\
\hline \multirow[t]{2}{*}{ Educational level } & Diploma & 62 & 15 \\
\hline & Degree and above & 350 & 85 \\
\hline \multirow[t]{3}{*}{ Ethnicity } & Amhara & 363 & 88.1 \\
\hline & Tigray & 25 & 6.1 \\
\hline & Oromo & 24 & 5.8 \\
\hline \multirow[t]{3}{*}{ Religion } & Orthodox & 371 & 90 \\
\hline & Muslim & 33 & 8 \\
\hline & Protestant & 8 & 2 \\
\hline \multirow[t]{3}{*}{ Position } & Junior nurse & 195 & 47.3 \\
\hline & Senior nurse & 185 & 44.9 \\
\hline & Nurse manager & 32 & 7.8 \\
\hline \multirow[t]{3}{*}{ Experience (years) } & $0-10$ & 357 & 86.7 \\
\hline & $11-20$ & 40 & 9.7 \\
\hline & $21-30$ & 15 & 3.6 \\
\hline \multirow[t]{3}{*}{ Working time } & Night & 22 & 5.34 \\
\hline & Day/Night & 237 & 57.52 \\
\hline & Day & 153 & 37.14 \\
\hline \multirow[t]{4}{*}{ Income (USD) } & $80.13-146.8$ & 77 & 18.7 \\
\hline & $146.9-2 \mid 3.5$ & 211 & 51.2 \\
\hline & $213.6-280.1$ & 105 & 25.5 \\
\hline & $280.2-346.8$ & 19 & 4.6 \\
\hline
\end{tabular}

Abbreviation: USD, United States Dollar.

proportion of moral distress was higher; in females 159 (46.1\%), single in marital status $165(87.8 \%)$, degree and above holders $25(92.6 \%)$, and in day/night shifting scheduled nurses 200 (84.4\%). Regarding the frequency of MD, $128(30 \%)$ reported very frequent moral distress (Figure 2).

\section{Bivariable and Multivariable Findings: Factors Associated with Moral Distress}

The binary logistic regression was used to test the association between variables. All independent variables were checked for association with the dependent variable using bivariate analysis. Variables with p-value $\leq 0.2$ in the bivariable logistic regression analysis were computed into the multivariable 


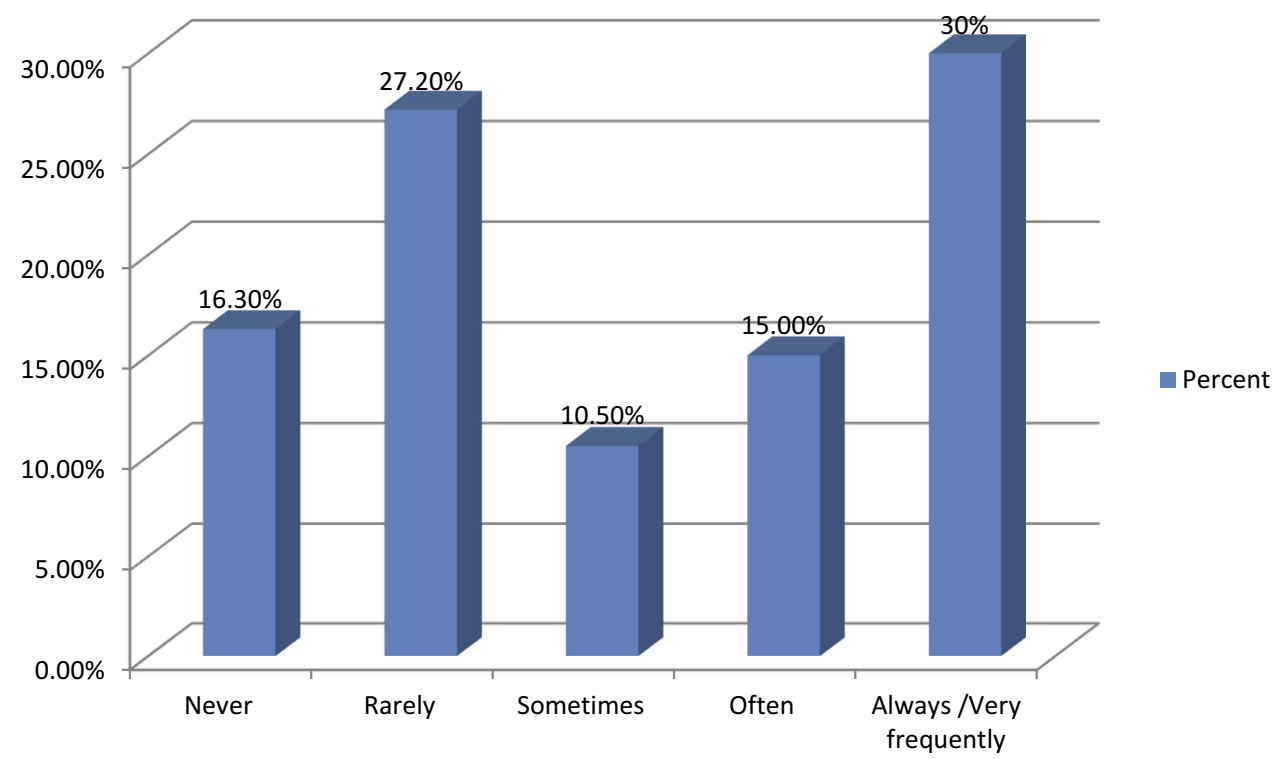

Figure 2 Frequency of Moral Distress among Nurses' in Northwest Amhara Regional State referral hospitals, Northwest Ethiopia, 2018 ( $n=4 \mid 2$ ).

logistic regression analysis. The $\mathrm{p}$-value $<0.05$ in multivariable logistic regression were considered as statistically significant. In multivariable logistic regression analysis; work experience $11-20$ years $[\mathrm{AOR}=2.0,95 \% \mathrm{CI}: 1.01,3.34]$, perceived poor team communication $[\mathrm{AOR}=4.54,95 \% \mathrm{CI}$ : 1.78 , 11.62], perceived powerlessness in decision making [AOR=3.3, 95\% CI:1.38, 7.87], inadequate staffing [AOR=2.96, 95\% CI:1.26, 6.97], and inappropriate provision of care $[\mathrm{AOR}=4.12,95 \% \mathrm{CI}: 1.55-10.9]$ were significantly associated with moral distress (Table 2).

\section{Discussion}

The proportion of moral distress was found to be $83.7 \%$ [ $95 \%$ CI: 79.6\%, 87.4\%]. Females and day or night shift scheduled nurses experienced frequent moral distress compared to others'. The finding of this study is in line with a study conducted in Belgium $80 \%{ }^{16}$ but, it was lower than a study in Rhode Island College $89 \% .{ }^{17}$ The difference could be attributed to the study period, socio-cultural variation, the knowledge and perception of participants, and study settings. Besides, there might be variation in sources of information, and working environment. The finding of the current study was higher than studies in the US (65\%), Canada (58\%), and Australia (72\%). ${ }^{18-20}$ The discrepancy might be due to the difference in data collection tools, work environment, sample size, organizational ethical climate, attitude, and knowledge of the participants.

Regarding factors associated with MD; nurses having 11-20 years of work experience were two times more likely to experience moral distress than nurses who had experience 0 to 10 years $[\mathrm{AOR}=2,95 \% \mathrm{CI}: 1.0,3.34]$. This is supported by a study conducted in Canada, the

Table 2 Bivariable and Multivariable Logistic Regression Analysis of Factors Associated with Moral Distress Among Nurses Working in, Northwest Amhara Regional State Referral Hospitals, Northwest, Ethiopia, $2018(n=412)$

\begin{tabular}{|c|c|c|c|c|}
\hline \multirow[t]{2}{*}{ Variables } & \multicolumn{2}{|l|}{ MD } & \multirow[t]{2}{*}{ COR, $95 \% \mathrm{Cl}$} & \multirow[t]{2}{*}{ AOR, $95 \% \mathrm{Cl}$} \\
\hline & Yes & No & & \\
\hline \multicolumn{5}{|l|}{ Work experience (years) } \\
\hline $0-10$ & 295 & 50 & 1.00 & 1.00 \\
\hline $1 \mathrm{I}-20$ & 40 & 12 & $2.06(1.0-4.23)$ & $2.0(1.0-3.34)^{*}$ \\
\hline $21-30$ & 10 & 5 & $3(1.98-9.14)$ & $0.26(0.02-4.65)$ \\
\hline \multicolumn{5}{|l|}{$\begin{array}{l}\text { Inappropriate provision } \\
\text { of care }\end{array}$} \\
\hline Yes & 275 & 31 & $4.56(2.64-7.89)$ & $4.123(1.55-10.9)^{* *}$ \\
\hline No & 70 & 36 & 1.00 & 1.00 \\
\hline \multicolumn{5}{|l|}{$\begin{array}{l}\text { Perceived powerlessness } \\
\text { in decision making }\end{array}$} \\
\hline Yes & 279 & 16 & $13.5(7.23-25.1)$ & $3.3(1.38-7.87) * *$ \\
\hline No & 66 & 51 & 1.00 & 1.00 \\
\hline \multicolumn{5}{|l|}{$\begin{array}{l}\text { Perceived poor team } \\
\text { communication }\end{array}$} \\
\hline Yes & 310 & 39 & $6.4(3.5-11.6)$ & $4.54(2.78-11.62)^{* *}$ \\
\hline No & 35 & 28 & 1.00 & 1.00 \\
\hline \multicolumn{5}{|l|}{ Inadequate staffing } \\
\hline Yes & 284 & 24 & $8.34(4.7 I-14.8)$ & $2.96(1.26-6.97)^{*}$ \\
\hline No & 61 & 43 & 1.00 & 1.00 \\
\hline
\end{tabular}

Notes: $*$-value $<0.05$, $* *$-value $<0.001$.

Abbreviations: COR, Crud Odds Ratio, AOR, Adjusted Odds Ratio. 
USA, and Egypt. ${ }^{19,21-23}$ In the nursing profession, the cumulative weight of distressing experiences is high.

Nurses who experienced perceived poor team communication are nearly five times more likely to have moral distress compared with nurses having good team communication $[\mathrm{AO}=4.54,95 \% \mathrm{CI}: 1.78,11.62]$. This is in line with a study done in Saudi Arabia. ${ }^{24}$ This might be due to lack of awareness or knowledge and skills held by colleagues from other disciplines and professions, the effect on staff relationships, staff dissatisfaction and patient outcomes of care, including adverse events, medical errors, and compromises in patient safety, perceived loss of autonomy. This supported by other studies done in New Zealand, Turkey and Brazil. ${ }^{25-27}$

Nurses who experienced perceived powerlessness are three times having probabilities to develop moral distress compared to unperceived powerlessness $[\mathrm{AOR}=3.395 \%$ CI: $1.38,7.87]$. It is supported by a study done in the USA and UK. ${ }^{18,28}$ This might be due to repetitive exposure to ethical dilemmas and limited collaboration in patient care decision making. Nurses' self-perceptions of powerlessness is a central theme in moral distress related to a lack of collaboration in patient care decision making and a lack of respect for their knowledge and expertise. ${ }^{29}$ Repetitive exposure to morally stressful events can also result in an intensity of symptoms as new situations may evoke stronger reactions due to the recall of earlier distressing situations. ${ }^{30,31}$

Nurses working in areas of inadequate staffing are nearly three times more likely to experience moral distress compared with an area with adequate staffing $[\mathrm{AOR}=2.96,95 \%$ CI, 1.26, 6.97]. This finding was in line with other studies in Iran and Uganda. ${ }^{13,32,33}$ This might be due to the shortage of human resources being able to be one of the most important factors in creating stress. Studies introduce a shortage of human resources and high workload as important factors in the creation of stress in the workplace. ${ }^{13,34}$ Nurses working in environments where there are insufficient staffing ratios jeopardize patient safety and depletes overworked and resources to perform nursing care may not be readily available because moral distress had a relationship with resources and staff adequacies. $^{26,35,36}$

Nurses who exercised inappropriate care four times more likely experienced moral distress than those nurses who delivered appropriate care $[\mathrm{AOR}=4.12,95 \% \mathrm{CI}: 1.55,10.9]$. This finding was supported by studies done in Malawi, India, and Netherland. ${ }^{37-39}$ Additionally, organizational ethical climate, limited resources, insufficient knowledge, and skill, as well as attitude of the nurses' decrease altruism, responsibility, experience and occupational interest of nurses are may influence nurses to deliver an inadequate quality of care. ${ }^{40-43}$

\section{Limitation of the Study}

This study did not assess the impact and the sign and symptoms of moral distress. The moral distress across the working unit was not assessed. Further research will be needed triangulated with qualitative design to explore the root cause of moral distress.

\section{Clinical Implication of the Study}

Delivering quality of health care is the ultimate goal of nurses and the hospital management to the patients/clients. Therefore, the study helps nurses to develop emotional wellbeing to deliver the quality of health care. It also helps the hospital managements to address and reduce moral distress among nurses in a clinical setting that affect their quality of life.

\section{Conclusion}

The proportion of moral distress among nurses was found to be high. Perceived poor team communication, inadequate staffing, perceived powerlessness in decision making, and inappropriate provision of care were factors associated with moral distress.

\section{Abbreviations}

AOR, adjusted odds ratio; COR, crude odds ratio; DMRH, Debre Markos Referral Hospital; FHRH, Felege Hiwot Referral Hospital; GURH, Gondar University Referral Hospital; MD, Moral Distress; MDS, Moral Distress Scale; MDS-R, Moral Distress Scale-Revised.

\section{Ethics Approval and Consent to Participate}

The study was approved by the University of Gondar, College of Medicine and Health Sciences, School of Nursing Ethical and Research Review Committee on the behalf of the University of Gondar Ethical Review Board with reference no. S/N 1205/2010 and was approved on $30 / 06 / 2010$ E.C. Permission and a supportive letter were obtained from each hospital. Written consent was obtained for each study participant and each study participant was informed about the purpose and benefit of the study. 


\section{Data Sharing Statement}

The raw data will not be provide for the reason of protecting client confidentiality, but the summary data are available in the main document.

\section{Acknowledgments}

The authors would like to express our gratitude to the University of Gondar College of Medicine and Health Sciences, School of Nursing, Ethical and Research Review Committee for ethical approval. The authors also acknowledge the data collectors and study participants.

\section{Author Contributions}

All authors contributed to data analysis, drafting or revising the article, gave final approval of the version to be published, and agree to be accountable for all aspects of the work.

\section{Disclosure}

The authors report no funding and no conflicts of interest in this work.

\section{References}

1. Savel RH, Munro CL. Moral Distress, Moral Courage. AACN; 2015.

2. Baldwin KM. Moral Distress and Ethical Decision Making. LWW; 2010.

3. Jameton A Nursing practice: The ethical issues. 1984.

4. Rautanen A, Baffoe-Mensah F, Zeh H Sources of Moral Distress Among registered Nurses. 2018.

5. Austin W. Moral distress and the contemporary plight of health professionals. HEC Forum. 2012;24:27-38. doi:10.1007/s10730-0129179-8

6. Berger JT. Moral distress in medical education and training. $J$ Gen Intern Med. 2013;29(2):395-398. doi:10.1007/s11606-013-2665-0

7. Kenyon M. Moral distress in nursing. Missouri Nurse Preceptor Acad. 2017;893-3700.

8. Connie M, Ulrich CG. Moral Distress in the Health Professions. Springer International Publishing; 2018.

9. Bureau of Labor Statistics CPS. Nursing: a profile of the profession. 2013.

10. O'Connell CB. Gender and the experience of moral distress in critical care nurses. Nurs Ethics. 2015;22(1):32-42. doi:10.1177/0969733013513216

11. Ebrahimi H, Nikravensh M, Oskouie F, Ahmadi F. Ethical behavior of nurses in decision-making in Iran. Iran J Nurs Midwifery Res. 2015;20(1):147-155.

12. Fariba Borhani MK, Abbaszadeh A. Moral self-concept and moral sensitivity in Iranian nurses. J Med Ethics History Med. 2015;8(4).

13. Vaziri MH, Merghati-Khoei E, Tabatabaei S. Moral distress among Iranian nurses. Iran J Psychiatry. 2015;10(1):32-36.

14. Corley MC. Nurse moral distress: a proposed theory and research agenda. Nurs Ethics. 2002;9(6):636-650. doi:10.1191/0969733002ne557oa

15. Mary CC, Elswick RK, Gorman M, Clor T. Development and evaluation of a moral distress scale. J Adv Nurs. 2001;33(2):25-256.

16. Lerkiatbundit S, Borry P. Moral distress Part I: critical literature review on definition, magnitude, antecedents and consequences. Thai J Pharm Pract. 2009;1:1.

17. Gonzalez J. Exploring the presence of moral distress in critical care nurses. Part of the Critical Care Nursing Common. 2016.
18. Mason VM, Leslie G, Clark K, Lyons P, Erica W, Griffin M. Compassion fatigue, moral distress, and work engagement in surgical intensive care unit Trauma nurses a pilot study. Dimen Crit Care Nurs. 2014;33:4. doi:10.1097/DCC.0000000000000056

19. Charles Philip Larson KDD-P, Gibbons C, Parshuram CS. Moral Distress in PICU and Neonatal ICU Practitioners: A Cross-Sectional Evaluation. Society of Critical Care Medicine and the World Federation of Pediatric Intensive and Critical Care Societies. 2017.

20. Trisha M, Prentice LG, Davis PG, Janvier A. Always a Burden? Healthcare Providers' Perspectives on Moral Distress. Australia; 2017.

21. Dodek PM, Wong H, Norena M, et al. Moral distress in intensive care unit professionals is associated with profession, age, and years of experience. J Crit Care. 2016;31:178-182. doi:10.1016/j.jcrc.2015.10.011

22. Qalawa SAA, Hassan HE. Implications of nurse's moral distress experience in clinical practice and their health status in obstetrics and critical care settings. Clin Pract. 2017;6(2):15-25.

23. Elpern EH, Cover B, Kleinpell R. Moraldistress of staff nurses in a medical intensive care unit. Am J Crit Care. 2005;14:6.

24. Abumayyaleh B, Khraisat O, Hamaideh S, Ahmed A, Thultheen I. Moral distress and turnover intention among critical care nurses in Saudi Arabia. Int J Nurs Health Sci. 2016;3(6):59-64.

25. Karagozoglu S, Yildirim G, Ozden D, inar ZC. Moral distress in Turkish intensive care nurses. Nurs Ethics. 2015;1-16.

26. Hirsch CD, Barlem ELD, Almeida L, Tomaschewski-Barlem JG, Lunardi VL, Pereira LA. The Occurrence of moral distress in nurses' professional routine Moral suffering in nursing. $J$ Nurs Socioenviron Health. 2014;1(2):205-211. doi:10.15696/2358-9884/jonse

27. Martin Woods VR, Towers A, La Grow. S. Researching moral distress among New Zealand nurses: a national survey. Nurs Ethics. 2014;1-14.

28. Young A, Froggatt K, Brearley SG. 'Powerlessness' or 'doing the right thing' - moral distress among nursing home staff caring for residents at the end of life: an interpretive descriptive study. Palliat Med. 2017;1-8.

29. Willis M Moral decisions, moral distress, and the psychological health of nurses. 2015.

30. Epstein EG, Hamric AB. Moral distress, moral residue, and the crescendo effect. J Clin Ethics. 2013;20(4):330-342.

31. Rushton $\mathrm{CH}$, Caldwell M, Kurtz M. Moral distress: a catalyst in building moral resilience. Am J Nurs. 2016;116:7.

32. Borhani F, Abbaszadeh A, Nakhaee N, Roshanzadeh M. The relationship between moral distress, professional stress, and intent to stay in the nursing profession. J Med Ethics History Med. 2014;7:4.

33. Jean N, Harrowing JM. Moral distress among Ugandan nurses providing HIV care: a critical ethnography. Int $J$ Nurs Stud. 2010;47:723-731. doi:10.1016/j.ijnurstu.2009.11.010

34. SIléN M. Encountering Ethical Problems and Moral Distress as a Nurse Experiences, Contributing Factors and Handling. 2011:20.

35. de Veer AJE, FRANCKE AL, STRUIJS A, WILLEMS DL, Determinants of moral distress in daily nursing practice: a cross-sectional correlational questionnaire survey. Int J Nurs Stud. 2013;50(1):100-108. doi:10.1016/j.ijnurstu.2012.08.017

36. Christodoulou-Fella M, Middleton N, Papathanassoglou EED, Karanikola MNK. Exploration of the association between nurses' moral distress and secondary traumatic stress syndrome: implications for patient safety in mental health services. Biomed Res Int. 2017;19.

37. Manchana V. Moral competence and perceived moral distress among health care professionals in an urban health care setting; Facility based study. Int J Sci Res. 2015;6:4.

38. Boer J, Rosmalen J, Bakker AB, Dijk M. Appropriateness of care and moral distress among neonatal intensive care unit staff: repeated measurements. Br Assoc Crit Care Nurses. 2015;21:3.

39. Veronica Mary Maluwa JA, Ndebele P, Chilemba E. Moral distress in nursing practice in Malaw. Nurs Ethics. 2012;19(2):196-207. doi:10.1177/0969733011414968 
40. Weinzimmer S, Miller SM, Zimmerman JL, Hooker J, Isidro S, Bruce CR. Critical care nurses' moral distress in end-of-life decisionmaking. J Nurs Educ Pract. 2014;4(6). doi:10.5430/jnep.v4n6p6

41. Wilson MA, Goettemoeller DM, Jennifer N. Moral distress: levels, coping and preferred interventions in critical care and transitional care nurses. J Clin Nurs. 2013;22:1455-1466. doi:10. 1111 jocn. 12128
42. McAndrew NS, Leske JS, Garcia A. Influence of moral distress on the professional practice environment during prognostic conflict in critical care. J Trauma Nurs. 2011;18:4. doi:10.1097/JTN.0b013e31823a4a12

43. Hamaideh SH. Moral distress and its correlates among mental health nurses in Jordan. Int J Ment Health Nurs. 2014;23:33-41. doi:10.1111/ inm.2014.23.issue-1

\section{Publish your work in this journal}

Psychology Research and Behavior Management is an international, peer-reviewed, open access journal focusing on the science of psychology and its application in behavior management to develop improved outcomes in the clinical, educational, sports and business arenas. Specific topics covered in the journal include: Neuroscience, memory and decision making; Behavior modification and management; Clinical applications; Business and sports performance management; Social and developmental studies; Animal studies. The manuscript management system is completely online and includes a very quick and fair peer-review system, which is all easy to use. Visit http://www. dovepress.com/testimonials.php to read real quotes from published authors. 